\title{
Predictors of Health Among Refugee Adults from Myanmar and the Development of Their Children
}

\author{
Peter Muennig • Prairie Boulmier-Darden • \\ Noor Khouzam $\cdot$ Wenyi Zhu $\cdot$ Paul Hancock
}

(C) Springer Science+Business Media New York 2014

\begin{abstract}
The objective of this study is to attempt to understand predictors of health among adult migrants from Myanmar to Thailand and predictors of development among their children. EQ5D5L scores and sociodemographic data were obtained among adult household members of children from two schools on the Thai/Myanmar border. Children were administered Ages and Stages questionnaires (ASQs). OLS and logistic regressions were used to examine predictors (e.g., witnessing gunfire) of various outcome measures (e.g., ASQ scores among children). In logistic regression analyses, maternal literacy proved to be a very strong predictor of the child's ASQ communication [17 ASQ points out of $60 ; 95 \%$ confidence interval (CI) 3, 31 points], problem solving (25 points; $95 \%$ CI 4, 45 points), and social skills ( 12 points; $95 \%$ CI 1,23 points) scores. A lower number of habitants/room predicted significantly better dentition among children [odds ratio (OR) 1.08, $95 \%$ CI 1.01, 1.67] and better social skills on the child's ASQ (12 points; $95 \%$ CI 1, 23 points).
\end{abstract}

P. Muennig $(\square)$

Mailman School of Public Health, Columbia University,

New York, NY, USA

e-mail:pm124@columbia.edu

P. Boulmier-Darden

Daystar Academy, Beijing, China

N. Khouzam

Englewood Hospital Program, Icahn School of Medicine at Mount Sinai, Englewood, NJ, USA

W. Zhu

PAREXEL China Co., Ltd, Shanghai, China

P. Hancock

Khom Loy Development Foundation, Chiang Rai, Thailand
Appliance ownership was a weak predictor of adult health, with those who own a refrigerator having about an $8 \%$ higher score on the EQ5D5L (1.08; $95 \%$ CI 1.01, 1.16). Finally, parents who witnessed gunfire tended to have children with ASQ scores that were 14 points lower than average in problem solving (95\% CI $-24,-4)$. Maternal education programs may have a very large impact on the development of their children. However, identifying those households at greatest need of resources is not a simple task, and will require a more complete census of communities at risk.

Keywords Refugee and immigrant health - Minority population health $\cdot$ Socioeconomic status and health

\section{Introduction}

Recently, Myanmar has opened up to the west economically and has begun a reconciliation process with its many ethnic groups [1]. While scattered conflicts remain throughout the country, many expect progress toward peace, democracy, and economic development to continue [2]. As a result, a good deal of aid is now flowing from the west to the Myanmar government, international aid organizations, and non-governmental organizations alike [3]. However, because the nation has been largely closed off to outside agencies for many decades, very little is known about the predictors of health and child development within ethnic minority areas [4-8].

With virtually no census data, little by way of formal education systems, and virtually no formal sector employment, it is very difficult for aid agencies to target their efforts to the neediest families [4-8]. Targeting is important because aid resources are necessarily limited and 
should go toward helping those households most in need [9]. Non-traditional predictors of health and childhood development, such as the history of conflict in an area, the number of habitants per room in households, or ownership of appliances, can serve as surrogate measures of family well-being when formal census data are not available [9]. We undertook this study both to understand the health needs of such populations in Karen State and to attempt to identify strategies for which the most at risk populations could be identified and therefore targeted with health and education interventions.

\section{Methods}

\section{Participants}

The Khom Loy Development Foundation (a non-governmental organization based in Thailand) collected extensive data on a sample of children and their parents from two schools in Mae Sot for internal evaluation purposes. These families represent a convenience sample of all children aged 3-6 (preschool/kindergarten) in these two schools. Because little is known about the needs of these populations, the authors requested that the Khom Loy Foundation provide access to these de-identified data for a secondary descriptive study of the refugee populations and their families. The study was found to be exempt from Institutional Review Board review by the Columbia University Institutional Review Board.

The descriptive information on the sample is presented in Table 1. In all, 122 participants (66 children and 56 parents) were interviewed. The study population is one parent and all children aged 3-6. Data on other household members was collected by proxy (an interview of the primary adult caregiver). The data reflect the parent who is the primary caregiver of the child, his/her exposure to war, his/ her assessment of the family's household, and his/her assessment of his/her own personal health.

\section{Data Collection and Measures}

Three instruments were used; a general household survey and the EuroQol (EQ5D-5L) were administered to adults and the Ages and Stages Questionnaire (ASQ) was administered to children. The general household interview contained questions pertaining to parental income, household appliance ownership, the number of people per room, whether the respondent had seen soldiers, whether the respondent had witnessed gunfire, and whether soldiers had harmed the respondent. The team also administered the EQ5D-5L, a widely used measure of health-related quality of life [10]. The EQ5D-5L consists of very simple ratings
Table 1 Socio-demographic characteristics of the analytic sample of adults, Khom Loy Development Foundation data, 2013

\begin{tabular}{lccc}
\hline & Mother & Father & Total \\
\hline Parents (n) & 53 & 49 & 102 \\
Count (\%) & & & \\
Literate & $44(81.48)$ & $49(94.23)$ & $93(87.74)$ \\
Occupational status & & & \\
Unemployed & $27(49.09)$ & $2(4.08)$ & $29(27.88)$ \\
Laborer & $26(47.27)$ & $44(89.8)$ & $70(67.31)$ \\
Professional & $2(3.64)$ & $3(6.12)$ & $5(4.81)$ \\
Has work permit & $33(62.26)$ & $31(63.27)$ & $64(62.75)$ \\
Educational attainment & & & \\
None & $13(24.07)$ & $7(14.89)$ & $20(19.80)$ \\
Less than high school & $35(64.81)$ & $33(70.21)$ & $68(67.33)$ \\
More than high school & $6(11.11)$ & $7(14.89)$ & $13(12.87)$ \\
EuroQol 5D-5L Score & & & \\
Mobility & & $1.4(0.7)$ & $1.2(0.5)$ \\
Self care & $1(0.0)$ & $1.8(0.6)$ & $1.7(0.6)$ \\
Usual activities & $1.6(0.6)$ & $1.1(0.3)$ & $1.1(0.3)$ \\
Pain/discomfort & $1.5(0.6)$ & $1.6(0.7)$ & $1.5(0.6)$ \\
Anxiety/depression & $1.5(0.6)$ & $1.8(0.8)$ & $1.7(0.7)$ \\
EQ-5D-5L index value & $0.8(0.1)$ & $0.7(0.1)$ & $0.7(0.1)$ \\
\hline
\end{tabular}

${ }^{a}$ The score represents an average value on a scale of $1-3$, where $1=$ no problems, $2=$ some problems, and $3=$ severe problems

(e.g., "I have no problems walking" on a scale of 1-5) that are easy to translate. The measure is preference-based, which means that the value assigned to each dimension (e.g., mobility, represented by the question above) is scored using subjective assessments from formal utility-based exercises. These assessments are scaled from zero to one, with zero being equal to death and one being equal to a state of perfect health. Unfortunately, weights are only available for certain nations. Of these weights, which were obtained from a relatively representative sample of the population, the US is likely the most ethnically diverse. Therefore US weights were used to score the tool [11]. While the use of non-culturally-aligned weights can skew absolute values assigned to health-related quality of life, it is not likely to affect the relative ranking of conditions, and should have minimal impact on the magnitude of the coefficient (which, in any case can be difficult to interpret on its own) [12].

The age 54 month ASQ was administered to all children in the study [13]. The ASQ generally consists of tasks rather then test questions, rendering it easy to administer in cross-cultural settings. The questionnaire is divided into the following categories: gross motor, fine motor, communication, problem solving and personal-social. The questions were read to participants by one of two multi-lingual interviewers who were fluent in every language spoken by 
the parents and children in the sample (Burmese, Karen, and Shan).

With respect to the ASQ, the same sets of identical materials were used to assess all children. The ASQ was administered to children who were removed from the classroom in groups of roughly three children, who were then separated. The surroundings were similar in all settings (a shaded, quiet outdoor space just outside of the classroom). However, given the large number of children per classroom and the limited staff resources, it was not always possible to keep other children from entering the test environment. Dental data were collected by a medical doctor who conducted a brief visual examination of the child's mouth and rated dentition by the number of teeth with visible decay.

The outcome measures studied here included overall EQ5D5L scores (continuous), ASQ scores on subsets of the test (continuous) by domain, and dentition (good/poor). Good dentition was defined as the absence of visible carries or decay and poor dentition was defined as the presence of any sign of tooth decay. Household income, appliance ownership, whether the father possessed a work permit in Thailand, parental educational attainment, the number of people per room in the household, and whether the participants witnessed gunfire were used as predictors of interest. Other predictors were excluded because responses were either very common or relatively rare (e.g., virtually all parents had seen soldiers, but relatively few had reported being physically harmed by soldiers) or eliminated a priori to reduce the total number of variables under study.

The actual age of the participants (whether children or adults) was not always known because not all parents know how to read a calendar or possess one.

\section{Analysis}

Logistic regression analyses was performed using STATA 12.0 and converted logits to odds ratios for easy interpretation of the dentition data. The EQ5D-5L models pertained only to adults within a relatively tight age range and were first specified with gender, marital status, and income as covariates, and then run again with refrigerator ownership (yes or no) substituted for income. The dentition and ASQ models were similarly specified. Although the children participating were roughly aged 4-6, age was included in the ASQ model to reduce cross group variation in age (because all children were administered the 54-month ASQ regardless of their age). The ASQ score deviations reported for each measure are reported relative to the sample mean, and are therefore standardized to the present study population.
Table 2 Socio-demographic characteristics of the analytic sample of households, Khom Loy Development Foundation data, 2013

\begin{tabular}{lc}
\hline Mean (SD) & \multicolumn{1}{c}{ Total } \\
\hline Number of siblings (of sample child) & $2.74(1.5)$ \\
Number of rooms & $1.5(0.7)$ \\
Number of people sleeping in each room $^{\mathrm{a}}$ & $3.8(1.4)$ \\
Monthly income (THB) $^{\mathrm{a}}$ & $8,212(10,940)$ \\
Annual income (THB) $^{\mathrm{a}}$ & $82,977(79,614)$ \\
Count (\%) & \\
Married & $46(86.79)$ \\
Owns refrigerator & $20(38.46)$ \\
Exposure to war & \\
$\quad$ Seen soldiers & $46(85.19)$ \\
Witnessed gunfire & $24(43.64)$ \\
Approached by soldier & $10(18.18)$ \\
Witnessed death & $21(38.18)$ \\
Harmed by solider & $11(20.37)$ \\
Religion & \\
Buddhism & $50(90.91)$ \\
Christianity & $3(5.45)$ \\
Islam & $2(3.64)$ \\
\hline
\end{tabular}

${ }^{a}$ At the time of press, $\$ 1=31$ Thai baht $(\mathrm{THB})$

The study had adequate sample size to detect approximately a $10 \%$ change in EQ5D scores (at a beta of 0.8 , and an alpha of 0.05), which was the pre-defined threshold for clinical significance.

\section{Results}

Table 1 lists the parental characteristics of the analytic sample. Roughly $88 \%$ of the parents were literate, but more males were literate (roughly $95 \%$ ) than females (about $81 \%$ ). About half of all females were unemployed, but very few males were jobless. Nevertheless, roughly equal percentages of females and males had work permits. With respect to language (data not shown), roughly $45 \%$ were monolingual in Burmese, with males slightly more likely (roughly $50 \%$ ) to be multilingual than females (roughly $40 \%$ ). About $15 \%$ spoke Thai only. As for health measures, the average female had an EQ5D-5L score of 0.75 and the average male had a score of 0.66 (on a score of zero to 1 ).

Table 2 lists the household characteristics. The annual household income was nearly 83,000 baht (about $\$ 2,700$ or $\$ 7 /$ day). These relatively high earnings were likely facilitated by high marriage rates (about $87 \%$ ). About $38 \%$ of the households owned a refrigerator. The vast majority of the households had at least one family member who had seen Burmese soldiers, $38 \%$ had witnessed death, and 
Table 3 Socio-demographic characteristics of the analytic sample of children, Khom Loy Development Foundation data (2013)

\begin{tabular}{lccc}
\hline Mean (SD) & Male child & Female child & Total \\
\hline Count (\%) & & & \\
Age & & & \\
4 & $7(21.88)$ & $10(29.41)$ & $17(25.76)$ \\
5 & $19(59.38)$ & $14(41.18)$ & $33(50)$ \\
6 & $6(18.75)$ & $10(29.41)$ & $16(24.24)$ \\
Ethnicity & & & \\
Burmese & $20(66.67)$ & $25(73.53)$ & $45(70.31)$ \\
Karen & $2(6.67)$ & $3(8.82)$ & $5(7.81)$ \\
Thai & $8(26.67)$ & $6(17.65)$ & $14(21.88)$ \\
Dentition & & & \\
No cavities & $7(31.82)$ & $4(14.81)$ & $11(22.45)$ \\
Poor & $15(68.18)$ & $23(85.19)$ & $38(77.55)$ \\
ASQ score & & & \\
Communication & $47.4(18.1)$ & $45.6(20.7)$ & $46.5(19.2)$ \\
Gross motor & $56.2(7.1)$ & $55.4(14.3)$ & $55.8(11.3)$ \\
Fine motor & $45(11.5)$ & $39.6(16.5)$ & $42.3(14.3)$ \\
Problem solving & $32(18.7)$ & $28.1(19.0)$ & $30(18.7)$ \\
Personal-social & $50.4(13.14)$ & $48.2(14.4)$ & $49.3(13.7)$ \\
\hline
\end{tabular}

$20 \%$ had actually been harmed by a soldier. About $91 \%$ of the sample parents reported Buddhism as their religion, with the remaining roughly equally distributed as Christian and Muslim. The average household had about four children.

Table 3 lists the characteristics of the children in the sample. Male and female children had roughly similar ASQ scores. About $70 \%$ of the parents self-identified their children as Burmese, with only $8 \%$ identifying as Karen, and $22 \%$ as Thai.

Finally, in logistic regression analyses, maternal literacy turned out to be a very strong predictor of the child's ASQ communication score [17 points; $95 \%$ confidence interval $(\mathrm{CI})=3,31$ points], problem solving ( 25 points; $95 \%$ CI 4, 45 points), and social skills (12 points; $95 \%$ CI 1, 23 points) scores. A larger number of habitants/room predicted significantly worse dentition [odds ratio (OR) 1.08, $95 \%$ CI 1.01, 1.67] and better social skills among children (12 points; $95 \%$ CI 1, 23 points). Appliance ownership was a weak predictor of adult health, with those who own a refrigerator having about an $8 \%$ higher score on the EQ5D5L (OR 1.08, $95 \%$ CI 0.01, 0.16) than those without. Finally, parents who witnessed gunfire tended to have children with ASQ scores that were 14 points lower than average in problem solving (95\% CI $-24,-4)$. All other health or development predictors were neither clinically nor statistically significant (Table 4).

\section{Discussion}

The descriptive analyses presented here indicate that the migrant population from Myanmar to Thailand is in high need of assistance. The health of these young parents is quite poor, the general level of development of the children is quite low, and there is a great need for dental hygiene. For example, the average EQ5D score for these 25-35-year-old parents was 0.7, roughly the health status of Americans who are 50 years old [14]. While not necessarily comparable across cultures, a score this low portends considerable chronic illness and a low healthy life expectancy.

Despite this clear need for assistance, targeting those households most in need will not be a simple task. Many of the predictors studied here were only weakly correlated with the outcome measures, and none stood out as clearly superior for identifying at risk populations. This suggests that a more complete census of migrant communities will be needed for improved targeting by international aid agencies. One exception to this rule is exposure to war. It is quite easy to identify villages that have been more heavily involved in conflict. The data from the present survey suggests that these geographically-defined areas should be a priority for intervention.

While it may be difficult for aid agencies to identify atrisk households, one mode of intervention clearly stood out. Female literacy efforts could go a long way toward improving the educational prospects of future generations. Female literacy has long been known to predict lower fertility, lower poverty and better health outcomes among both mothers and children in developing contexts $[15,16]$. However, relatively less data exist on development outcomes among children, with most of the literature focused on economically developed contexts [17]. The impact of maternal literacy on child development was larger than observed in the scientific literature.

This brief report was subject to a number of important limitations. First, the sample size was limited. While there was adequate statistical power to detect moderate effect sizes, it could be that factors such as income, appliance ownership, and overcrowding would hold together more cohesively were there adequate power to detect smaller effect sizes. Second, the sample was drawn from a convenience sample at two schools in one town in Thailand. The advantage of drawing from schools is that it allows for a larger catchment of refugee households than a random survey within a given community or neighborhood. The disadvantage is that it only allows for surveying families with children in school (and may therefore miss the most disadvantaged families who do not send their children to school), and that it is not a random sample. Few adult refugees from Myanmar know their chronological age in part because literacy rates are low and few households have 
Table 4 Sociodemographic predictors of adult health and child dentition, communication skills, gross and fine motor skills, problem solving skills, and social skills

\begin{tabular}{|c|c|c|c|c|c|c|c|}
\hline & EQ5D5L ${ }^{\mathrm{a}}$ & Dentition & Communication & Gross motor & Fine motor & $\begin{array}{l}\text { Problem } \\
\text { solving }\end{array}$ & Social \\
\hline High income ${ }^{\mathrm{b}}$ & $\begin{array}{l}0.02 \\
(-0.04,0.09)\end{array}$ & $\begin{array}{l}0.78 \\
(0.17 \text { to } \\
3.55)\end{array}$ & $\begin{array}{l}-0.51 \\
(-11.77 \text { to } \\
10.75)\end{array}$ & $\begin{array}{c}-2.07 \\
(-9.05 \text { to } \\
4.91)\end{array}$ & $\begin{array}{l}2.03 \\
(-6.28 \text { to } \\
10.34)\end{array}$ & $\begin{array}{l}4.10 \\
(-6.24 \text { to } \\
14.43)\end{array}$ & $\begin{array}{l}-2.42 \\
(-11.30 \text { to } \\
6.46)\end{array}$ \\
\hline $\begin{array}{l}\text { Father has a work } \\
\text { permit }\end{array}$ & $\begin{array}{l}0.01 \\
(-0.07 \text { to } \\
0.09)\end{array}$ & $\begin{array}{l}1.25 \\
(0.19 \text { to } \\
8.40)\end{array}$ & $\begin{array}{l}-6.07 \\
(-18.75 \text { to } \\
6.62)\end{array}$ & $\begin{array}{l}3.34 \\
(-5.17 \text { to } \\
11.85)\end{array}$ & $\begin{array}{l}-1.48 \\
(-11.31 \text { to } \\
8.36)\end{array}$ & $\begin{array}{l}-4.24 \\
(-15.57 \text { to } \\
7.08)\end{array}$ & $\begin{array}{l}-0.78 \\
(-10.80 \text { to } \\
9.25)\end{array}$ \\
\hline $\begin{array}{l}\text { Father high school } \\
\text { graduate }\end{array}$ & $\begin{array}{l}0.00 \\
(-0.14 \text { to } \\
0.14)\end{array}$ & & $\begin{array}{l}-3.03 \\
(-28.71 \text { to } \\
22.66)\end{array}$ & $\begin{array}{l}4.11 \\
(-11.00 \text { to } \\
19.23)\end{array}$ & $\begin{array}{l}4.91 \\
(-13.54 \text { to } \\
23.36)\end{array}$ & $\begin{array}{c}16.50 \\
(-7.33 \text { to } \\
40.33)\end{array}$ & $\begin{array}{l}0.23 \\
(-20.02 \text { to } \\
20.49)\end{array}$ \\
\hline Mother's literacy & $\begin{array}{l}0.04 \\
(-0.04 \text { to } \\
0.12)\end{array}$ & $\begin{array}{l}0.56 \\
(0.06 \text { to } \\
5.50)\end{array}$ & $\begin{array}{l}\text { 17.07 } \\
(\mathbf{3 . 3 6} \text { to } \mathbf{3 0 . 7 7})\end{array}$ & $\begin{array}{l}1.63 \\
(-7.92 \text { to } \\
11.18)\end{array}$ & $\begin{array}{l}0.60 \\
(-10.69 \text { to } \\
11.89)\end{array}$ & $\begin{array}{l}24.96 \\
(4.47 \text { to } 45.45)\end{array}$ & $\begin{array}{l}11.89 \\
(0.94 \text { to } 22.84)\end{array}$ \\
\hline Father's literacy & $\begin{array}{c}-0.01 \\
(-0.11 \text { to } \\
0.10)\end{array}$ & $\begin{array}{l}1.38 \\
(0.09 \text { to } \\
21.70)\end{array}$ & $\begin{array}{l}2.68 \\
(-25.88 \text { to } \\
31.25)\end{array}$ & $\begin{array}{c}-2.86 \\
(-20.28 \text { to } \\
14.56)\end{array}$ & $\begin{array}{l}-6.39 \\
(-26.38 \text { to } \\
13.60)\end{array}$ & $\begin{array}{l}6.00 \\
(-18.78 \text { to } \\
30.78)\end{array}$ & $\begin{array}{l}-4.66 \\
(-26.48 \text { to } \\
17.16)\end{array}$ \\
\hline Habitants/room & $\begin{array}{l}0.06 \\
(-0.032 \text { to } \\
0.15)\end{array}$ & $\begin{array}{l}\mathbf{0 . 0 8} \\
(\mathbf{0 . 0 1} \text { to } \\
\mathbf{0 . 6 7})\end{array}$ & $\begin{array}{l}8.06 \\
(-7.05 \text { to } \\
23.18)\end{array}$ & $\begin{array}{l}4.76 \\
(-4.77 \text { to } \\
14.29)\end{array}$ & $\begin{array}{l}0.19 \\
(-11.09 \text { to } \\
11.46)\end{array}$ & $\begin{array}{l}8.48 \\
(-5.55 \text { to } \\
22.51)\end{array}$ & $\begin{array}{l}12.28 \\
(0.94 \text { to } 23.62)\end{array}$ \\
\hline \multicolumn{8}{|l|}{ Married } \\
\hline Owns refrigerator & $\begin{array}{l}\mathbf{0 . 0 8} \\
(0.01 \text { to } 0.16)\end{array}$ & $\begin{array}{l}0.58 \\
(0.09 \text { to } \\
3.64)\end{array}$ & $\begin{array}{c}-0.25 \\
(-12.62 \text { to } \\
12.13)\end{array}$ & $\begin{array}{l}1.35 \\
(-7.12 \text { to } \\
9.81)\end{array}$ & $\begin{array}{l}-0.99 \\
(-11.41 \text { to } \\
9.44)\end{array}$ & $\begin{array}{l}5.55 \\
(-5.86 \text { to } \\
16.96)\end{array}$ & $\begin{array}{l}1.81 \\
(-7.83 \text { to } \\
11.44)\end{array}$ \\
\hline Witnessed gunfire & $\begin{array}{c}-0.01 \\
(-0.08 \text { to } \\
0.06)\end{array}$ & $\begin{array}{l}0.51 \\
(0.10 \text { to } \\
2.68)\end{array}$ & $\begin{array}{l}-10.05 \\
(-21.34 \text { to } \\
1.23)\end{array}$ & $\begin{array}{l}-6.85 \\
(-13.72 \text { to } \\
0.02)\end{array}$ & $\begin{array}{l}-7.32 \\
(-15.57 \text { to } \\
0.92)\end{array}$ & $\begin{array}{c}-14.12 \\
(-23.80 \text { to } \\
-4.45)\end{array}$ & $\begin{array}{l}-7.70 \\
(-16.40 \text { to } \\
1.01)\end{array}$ \\
\hline
\end{tabular}

Most relevant measures are highlighted in bold

${ }^{\text {a }}$ Measures on a scale from zero to one

b 72,000 baht or more relative to less than 72,000 baht

or know how to read calendars. For this reason, the age data used represent best guesses on the parts of parents. If illiterate mothers systematically bias their children's ages relative to literate mothers, this bias could account for the powerful associations between maternal literacy and childhood ASQ performance that was observed. However, the proportion of illiterate parents was less than $15 \%$ (a surprisingly low figure), suggesting that any such bias would be minimal.

\section{Conclusions}

It is hoped that this brief report will be useful to nongovernmental organizations, governmental agencies, and international agencies in helping to understand the risk factors for poor health and education outcomes among former refugee populations. As Myanmar modernizes and progresses toward democracy, it is now possible to easily deliver services to low-income households within that country. One of the most important of these interventions will be ongoing female literacy and education campaigns for young adults, and improved schooling for children.

In a low resource setting, it is useful to develop alternatives to expensive surveys or census data collection efforts [9]. Surveys of appliance ownership or overcrowding in the home are plausible alternatives to direct measures of household income. An even easier strategy for targeting involves identifying areas that were most exposed to civil war. Not only are such data easier to collect, they are not subject to the same reporting bias that income might be. However, only female literacy was a reliable predictor of the outcomes of interest presented here, and this type of variable requires household census data. On the other hand, the strong association between childhood developmental outcomes and maternal literacy does suggest that female literacy interventions are strongly needed. Finally, in line with data from other post-conflict settings $[18,19]$, the study finds that the negative parental exposure to war exerts powerful effects not only on those who were 
directly exposed, but also on future generations, impacting a range of measures of well-being in adults and children.

\section{New Contribution to the Literature}

At a time when international aid operations are ramping up in Myanmar (also known as Burma) alarmingly little is known about the health needs of Myanmar's minority populations. We undertook this study both to understand the health needs of such populations in Karen State and to attempt to identify strategies for which the most at risk populations could be identified and therefore targeted with health and education interventions.

Acknowledgments The Khom Loy Development Foundation gratefully acknowledges funding from UBS-Optimus Foundation on research about the importance of early child development.

\section{References}

1. Prakash A. The economic transition in Myanmar: towards inclusive, people centered and sustainable economic growth. PB2013-03, Working papers from Economic Research Institute for ASEAN and East Asia (ERIA); 2013.

2. Okamoto I. Comment on "Toward Myanmar's new stage of development: transition from military rule to the market". Asian Econ Policy Rev. 2013;8(1):120-1.

3. Mieno F. Toward Myanmar's new stage of development: transition from military rule to the market. Asian Econ Policy Rev. 2013;8(1):94-117.

4. Lee TJ, Mullany LC, Richards AK, Kuiper HK, Maung C, Beyrer C. Mortality rates in conflict zones in Karen, Karenni, and Mon states in eastern Burma. Trop Med Int Health. 2006;11(7):1119-27.

5. Kemmer TM, Bovill ME, Kongsomboon W, Hansch SJ, Geisler $\mathrm{KL}$, Cheney $\mathrm{C}$, et al. Iron deficiency is unacceptably high in refugee children from Burma. J Nutr. 2003;133(12):4143-9.
6. Su C, Muennig P. The politics of social entrepreneurs in access to education: a case study of Shan Burmese refugees in Northwest Thailand. Curr Issues Comp Educ. 2005;8(1):31-40.

7. Verma N, Chan C, Su S, Muennig PA. Between "voluntary migrants" and war refugees: the health of the Shan Burmese migrant workers in northern Thailand. J Immigr Refug Stud. 2011;4(9):452-9.

8. Zhao A, Zhang Y, Peng Y, Li J, Yang T, Liu Z, et al. Prevalence of anemia and its risk factors among children 6-36 months old in Burma. Am J Trop Med Hyg. 2012;87(2):306-11.

9. Coady DP, Grosh ME, Hoddinott J. Targeting of transfers in developing countries: review of lessons and experience. World Bank-free PDF. 2004. http://siteresources.worldbank.org/SAFE TYNETSANDTRANSFERS/Resources/281945-1138140795625/ Targeting_En.pdf. Accessed 15 May 2014.

10. Rabin R, de Charro F. EQ-5D: a measure of health status from the EuroQol Group. Ann Med. 2001;33:337-43.

11. Johnson JA, Coons SJ, Ergo A, Szava-Kovats G. Valuation of EuroQOL (EQ-5D) health states in an adult US sample. Pharmacoeconomics. 1998;13(4):421-33.

12. Gold MR, Muennig P. Measure-dependent variation in burden of disease estimates: implications for policy. Med Care. 2002;40(3): 260-6.

13. Squires J, Bricker D, Potter L. Revision of a parent-completed developmental screening tool: Ages and Stages Questionnaires. J Pediatr Psychol. 1997;22(3):313-28.

14. Muennig PA, Gold MR. Using the years-of-healthy-life measure to calculate QALYs. Am J Prev Med. 2001;20(1):35-9.

15. Desai S, Alva S. Maternal education and child health: is there a strong causal relationship? Demography. 1998;35(1):71-81.

16. Payne AC, Whitehurst GJ, Angell AL. The role of home literacy environment in the development of language ability in preschool children from low-income families. Early Child Res Q. 1994; 9(3):427-40.

17. Bradley RH, Corwyn RF. Socioeconomic status and child development. Annu Rev Psychol. 2002;53(1):371-99.

18. Joshi PT, O'donnell DA. Consequences of child exposure to war and terrorism. Clin Child Fam Psychol Rev. 2003;6(4):275-92.

19. Macksoud MS, Aber JL. The war experiences and psychosocial development of children in Lebanon. Child Dev. 1996;67(1):70-88. 